\title{
Factors that Predict Attitudinal Grouping towards SMS Advertising
}

\author{
https://doi.org/10.3991/ijim.v12i5.8985 \\ Michael Humbani( $\left.{ }^{\bowtie}\right)$, Yolanda Jordaan \\ University of Pretoria, South Africa \\ michael.humbani@up.ac.za
}

\begin{abstract}
This study focuses on factors that predict consumer attitudes towards short message service (SMS) advertising. The purpose of the study is to build a predictive framework that can be employed to identify which factors of SMS advertising contribute to different attitudinal groups. This study is based on the push and pull motivation theory which, in this context, explains and predicts consumer responses to SMS advertisements. The results of the discriminant analysis indicate that three factors of SMS advertising are responsible for group separation, namely perceived SMS infotainment, perceived knowledge and fear of spamming. The discriminant model enables practitioners to predict the category to which consumers belong based on their responses to the factors of SMS advertising, and allows media practitioners to use SMS advertising more effectively.
\end{abstract}

Keywords - discriminant analysis, attitudinal groups, SMS advertising, SMS infotainment, group membership.

\section{$1 \quad$ Introduction}

Within the past decade, the mobile telephone has become one of the most ubiquitous communication devices the world over [8]. As such, the mobile phone has become a handy tool that has profoundly changed not only the ways of communication, but also several facets of people's lives [35]. One area that is experiencing exponential growth is the use of short message service advertisements (SMS). According to Zabadi et al. [45], SMS advertisements have been the most successful non-voice service for mobile operators in the history of telecommunications. Hence, SMS advertisements have been a key revenue generator with many companies using SMS advertising to reach their target markets. It has been estimated that global mobile advertising spending would reach $\$ 247.4$ billion by 2020 [34]. As SMS advertisements via mobile phones become an increasingly important channel for the marketing and communication of products and services, it is imperative to understand consumers' attitudes and behavioural intentions towards the use of SMS as a promotional channel [42].

Literature on SMS advertisements has revealed several key factors which play a role in the effective implementation of SMS advertisements. Beneke et al. [5] pro- 
posed a conceptual model to explain factors that influence consumer attitudes towards SMS advertising among the youth. The model by Beneke et al. [5] has been used and expanded in other studies to determine consumers' attitudes towards SMS advertisements [18]. This study draws on Beneke et al.'s [5] existing model to build a predictive framework that can be employed to identify homogenous consumer groups with regard to their attitudes towards SMS advertising.

Nitalla [23] reported that communications via mass media are on the decrease as more direct and highly targeted promotional activities are gaining momentum. Using the mobile phone for SMS advertising allows real-time communication with consumers at any time, in addition to SMS advertising's benefit of simplicity, reach, low cost and reliability $[37,45]$. For this reason, astute media planners are now shifting from traditional marketing to new, interactive, digital media based on a more targeted approach through personalised channels [32]. Thus, SMS advertisements are gaining global interest from both scholars and practitioners. Despite the growth in academic research regarding SMS advertising, [5, 16, 44], the literature is almost silent on the factors that classify consumers on the basis of their attitudes towards SMS advertisements.

Several factors drive the attitudes towards SMS advertising and it is necessary to differentiate between consumers with favourable and those with less favourable attitudes towards SMS advertising, based upon these factors. Marketers frequently want to change consumer attitudes towards their products and services, and they focus their attention on developing persuasive messages [3]. The classification of consumers may offer suggestions to practitioners to develop media strategies that may persuade consumers with less favourable attitudes to increase their favourability towards SMS advertising. For example, practitioners can focus on improving consumer attitudes for factors that were evaluated positively or can focus on decreasing the strength of beliefs regarding negatively evaluated factors. As reported by Dolnicar and Jordaan [11], consumers differ in their attitudes towards different forms of advertising and, as such, managing attitudes towards SMS advertising according to consumer heterogeneity may have value for media practitioners. Baron and Segerstad [4] reported that consumers can be characterized by parameters that can allow media practitioners to predict, at least statistically, how members of those groups are likely to behave when they receive SMS advertisements. In many countries, text messaging is rampant among teenagers and young adults, while older adults do more talking [4]. Therefore, a discriminant analysis was conducted to predict group membership in terms of attitudes towards SMS advertising to assist managers in developing and implementing effective market segmentation strategies.

The remainder of the article is organised as follows: first, a theoretical foundation with research questions are presented, followed by a discussion of the research methodology. Next, the empirical findings are presented, including limitations of the study, and concludes with the implications for marketing and media practitioners. 


\section{Development of the conceptual framework}

This study is based on Dann's [9] the push and pull motivation theory which, in this context, explains and predicts consumer responses to SMS advertisements that they receive. The push strategy is traditionally the most adopted model for sending text messages by media practitioners as it seeks to boost sales [24]. A push marketing campaign assumes that consumers have given consent or have subscribed to receiving information on offers or updates from a company through the channel of SMS [22]. However, scholars believe that the push strategy is tantamount to sending unsolicited messages which the sender believes can catch the attention of the receiver. With the pull strategy, the communicator sends the information requested by the consumer [24]. The pull strategy thus corresponds to sending messages whose content or services have been previously searched for and requested by the users [1]. This study is grounded on the push model which has been widely reported in literature to be capable of producing responses to a much greater extent than traditional media because it allows one-to-one dialogue with consumers [10].

\subsection{Attitudes towards SMS advertising}

Consumer attitudes towards advertising have been largely examined because of their relation to consumer responses to advertisements [20]. Although there is some debate regarding a precise definition of consumer attitude, there is a general agreement that an attitude towards advertising can be viewed as "a learned predisposition to respond in a consistently favourable or unfavourable manner to advertising in general" [14]. Measuring and understanding consumer attitudes allow companies to develop the products consumers want, promote these products effectively and evaluate their efforts at promotion [14]. According to Babin and Harris [3], the term attitude refers to feelings, beliefs and behavioural intentions that influence the way in which individuals evaluate and respond to marketing communications. These authors contend that a customer's positive attitude towards a specific product will have an effect on how he or she responds to it in terms of not only the decision to buy or not to buy the product, but also whether to recommend the product to others or not. In this regard, several studies have reported that consumers who hold positive attitudes towards SMS advertisements were most likely to respond favourably to these advertisements [5], [16], [38].

This study draws upon Beneke et al.'s [5] model with the aim of determining which factors discriminate between consumers with a favourable and those with unfavourable attitudes towards SMS advertising. Beneke et al. [5] proposed eight factors based on three criteria, namely message elements, consumer profile and privacy issues. The factors relating to message elements are (1) content appeal, (2) perceived personalisation, and (3) interactivity of SMS advertisements. The factors that relate to the consumer profile include (4) attitudes towards advertising in general, (5) consumer innovativeness, and (6) perceived consumer knowledge. The last factors relating to privacy issues are (7) perceived control and (8) fear of spamming. In addition to the factors identified by Beneke et al. [5], a decision was taken to include two additional 
factors that have been identified in literature as significant predictors of SMS advertising. These factors are perceived incentives and location-based advertising [7], [12], [32]. These two additional factors relate to the message elements in the proposed framework because marketers consider them important to attract the attention of consumers to respond to SMS advertising. Thus, this study investigates the ten factors to develop an extended model beyond the sample of youth initially proposed by Beneke et al. [5]. Subsequently, these factors are explained in the section that follows.

\subsection{Predicting factors of consumer attitudes towards SMS advertising}

Message elements: Content appeal. Content appeal, also described as informativeness by Van der Waldt et al. [38], is the ability of advertising to inform consumers of product alternatives so that purchases yielding the greatest possible satisfaction can be made. In the context of this study, content appeal can be viewed as the ability of an SMS advertisement to deliver information to customers in order to satisfy their needs [20]. According to these authors, information received by consumers through mobile phones must demonstrate qualitative features such as accuracy, timeliness and usefulness to consumers. The value of consumer information in today's business environment is undeniable [11]. Thus, content appeal was found to be among the strongest contributing factors to consumer perceptions and attitudes by other scholars such as Aslam et al. [2], Beneke et al. [5] and Zabadi et al. [45].

Message elements: Personalisation of SMS advertisements. Personalisation, on the other hand, can provide media practitioners with an avenue to reach potential consumers individually, thus enhancing their relationships with consumers [37]. Personalisation refers to sending of advertising messages via mobile phones through wireless networks based on factors such as demographic information of consumers. Studies that investigated perceived personalisation reported that personalisation of an SMS advertisement is indeed effective in building consumers' attitudes towards SMS advertisements [5], [7], [37]. Conclusions from these studies indicate that overall, selecting the appropriate target market based on personal information, sending the users desired advertising messages, and creating personalised advertising content are important issues that will affect the degree of consumer acceptance towards SMS advertising and its effectiveness [7].

Message elements: Interactivity of SMS advertisements. Interactivity of SMS advertisements refers to the bi-directional nature of mobile phones which enables users to reply to SMS messages, thus making it possible for advertisers to establish a direct dialogue with their potential consumers [20]. Research indicates that interactive elements can convince the potential consumer to search for more information concerning the advertised product and can convince the potential consumer to give feedback to the advertiser [32]. Feedback from the consumer can be used by companies to customise products and services for effective SMS campaigns. Drossos et al. [12] reported that SMS advertisements offering an element of interactivity would lead to more positive attitudes towards the advertisement than those containing no interactive elements. This claim is consistent with previous researchers who reported that the 
level of interactivity of an SMS advertisement has a positive effect on the consumer's attitude towards SMS advertising [5].

Message elements: Perceived incentives. Another element used to enhance the effectiveness of SMS advertisements is the consumer's perception of incentives. Incentive-based advertising provides specific financial rewards to individuals who agree to receive information relating to promotions and campaigns [23]. Roozen and Genin [32] point out that providing incentives increases the intention to receive SMS advertisements. These findings were corroborated by Parreno et al. [23], who reported that monetary incentives invite consumers to take into consideration the acceptance of SMS advertisements on their mobile phones. Findings from a study conducted by Drossos et al. [12] also indicate that users expect a reward for receiving text advertisements, and that incentives allow consumers to overcome the uncertainty that accompanies unfamiliar products. As a result, advertisers often employ promotional incentives such as coupons, rebates, price packs and contests to boost product sales [12].

Message elements: Location-based advertising. Location-based advertising has also attracted attention over the years among scholars. According to Drossos et al. [12], location-based advertising entails the strategic positioning of advertisements near places where buyer behaviour can be easily influenced and quickly converted into a sale. Advanced technologies, such as Bluetooth, enhance the feasibility of applying Global Positioning System (GPS) technology that will allow advertisers to provide real-time offers to subscribers who are shopping in a specific store or driving in close proximity to a retail outlet [24]. These authors found that consumers do list location-based services as having considerable appeal because such services represent an important aspect of message relevance. In addition, Drossos et al. [12] claim that location-based SMS advertising helps in the formation of a favourable attitude when combined with incentives. Beneke et al. [5] also argue that location-based SMS advertising is viewed more favourably since messages are tailor-made according to consumers' needs. From these reports, there seems to be widespread agreement among researchers that location-based advertising has a positive effect on consumer attitudes towards SMS advertising.

Consumer profile elements: Attitudes towards SMS advertising in general. The relationship between attitude and acceptance of SMS advertisements has already been tested in previous research, and a strong correlation was found between the variables [5], [31], [38]. Since attitude is a "learned predisposition of human beings" [13], an individual will respond to an object, an idea, opinions or a number of other stimuli. Measuring and understanding consumer attitudes thus allows companies to develop appropriate products for the right target consumer. Consequently, the attitude which a consumer has towards a brand or an SMS advertisement has an impact on his/her intention to purchase the brand offering or respond to the advertisement [38].

Consumer profile elements: Consumers' innovativeness. Consumer innovativeness, although not commonly cited in literature, is also a central determinant of consumers' attitudes towards SMS advertisements. The adoption of new products or services in marketing is related to consumer innovativeness. Consumer innovativeness is the degree to which an individual is relatively earlier in adopting new ideas 
(SMS advertisements) as opposed to other members of his/her social system [19]. Studies that investigated consumer innovativeness indicate that young adults (16-24 years old) are more innovative than older consumers ( 25 years and up), because they frequently use their mobile phones [5], [39]. Reports by Orr et al. [25] and, Phau and Teah [29] indicates that consumer innovativeness is linked to mobile phone ownership and usage. The authors assert that a higher frequency of SMS usage shows greater acceptance of and familiarity with the use of mobile phone technology. This is echoed in another study by Gao et al. [16], which reported that the degree to which consumers are open to new experiences, information and technology directly influences their attitudes towards SMS advertising practices.

Consumer profile elements: Perceived knowledge. Perceived knowledge is also described as existing knowledge by Radder et al. [30] and refers to the ability of consumers to understand the features and usage of an innovation, and to realise its value. This suggests that an application perceived to be easier to use than another is more likely to be accepted by users. However, perceived knowledge is related to technological conditions of a given country and some countries' technological environment allows a sufficiently high volume of consumers to adopt the technologies [24]. For example, South Africa is characterised by a high level of technologies that are available to consumers as evidenced by the high mobile penetration rates that have surpassed the $150 \%$ mark [6]. In support of this, Yang et al. [44] reported that the more accepting consumers are of mobile technologies, the more they tend to respond to SMS advertisements. Thus, perceived knowledge can be considered a sufficient condition for attitude formation and actual response, as more experienced consumers are likely to have a lower level of uncertainty and perceived risk with regard to mobile advertisements [44].

Privacy issue elements: Perceived control. Perceived control can also influence the effectiveness of SMS advertisements. Since consumers are bombarded by large numbers of advertisements every day, they want to control the amount of advertising that they receive by filtering out excess visual stimuli [32]. According to Gao et al. [15], control is associated with minimising effort in the achievement of a task and ease of adding information. The authors further contend that the perception of full control over the content and the conversation of handheld devices is critical because handheld devices are often very personal gadgets. Users feel annoyed or even furious when they find that they cannot do anything about the messages pushed onto their mobile phones. Gao et al. [15] indicated that if participants in an interactive communication are able to exert control over the information exchange, they will develop positive attitudes towards the communication. Based on this, it can be said that consumer attitudes towards SMS advertising are likely to be influenced by the perceived control that they have over the SMS advertising messages they receive.

Privacy issue elements: Fear of spamming. Fear of spamming has been widely investigated to determine its impact on consumers' attitudes towards SMS advertisements. Available studies show that consumers' fear of spamming negatively impacts consumers' attitudes towards SMS advertisements [5], [16], [37]. Fear of spamming is defined as fear of receiving unsolicited advertising [45]. In their study, Parreno et al. [27] found that fear of spamming, also described as irritation, leads to a negative 
attitude towards SMS advertisements. Consistent with this finding, Wei et al. [41] reported that the mobile phone is a personal technology and as such, advertising on this medium has to depart from the bombardment and interruption model of advertising that characterises traditional media. In order to reduce fear of spamming, SMS advertisements must be sent only to consumers who have explicitly indicated their willingness to receive the advertisement [36].

\section{$3 \quad$ Methodology}

\subsection{Sample}

The target population for this study were individuals comprising staff and postgraduate students of higher education institutions aged 25 years and older, living in the Gauteng province in South Africa at the time of the survey. Previous studies have focused primarily on consumers aged between 16 and 24 years of age [5, 25]. To provide a wider spectrum of consumer attitudes towards SMS advertising, the study focused on consumers aged 25 years and older. Permission to collect data was granted from three higher education institutions in the Gauteng province, which is the most populous province in South Africa. A convenience sample of 304 consumers was drawn, which is sufficiently large for the purpose of discriminant analysis [23]. The respondents included 136 males and 168 females. In terms of ethnicity, the majority of the respondents were Africans (76\%) followed by Whites (15\%), Indians (6\%) and other minority ethnic groups in South Africa (3\%). The age distribution of respondents was as follows: $25-30$ years old (36\%), 31-40 years old (40\%), and 41 years and older $(24 \%)$.

\subsection{The measurement instrument}

A pre-tested self-administered questionnaire was used. The measurement instrument included 47 questions and consisted of three sections. The first section contained 40 Likert-type response format questions ranging from (1) strongly disagree to (7) strongly agree measuring consumers' attitudes towards SMS advertising. The scale items for consumer attitudes towards advertising in general, innovativeness and knowledge were adapted from Radder et al. [30]. Scales for content appeal, perceived incentives, perceived control and perceived personalisation were adapted from Unal et al. [37]. Scales for fear of spamming, and interactivity were adapted from Gao et al. [16] while scales for location-based advertising were adapted from Chen and Hsieh [7]. The second section of the questionnaire comprised three questions relating to SMS usage and the amount of money that consumers spend on SMSs per month. The third section included questions to capture the demographic profiles of the respondents. Data were collected by handing the questionnaire to (a) postgraduate students at the universities that offer postgraduate studies in the Gauteng province, and (b) staff members at the same universities during office hours. 


\subsection{Data analysis}

Firstly, a Principal Components Analysis (PCA) was performed to validate the measures of the ten constructs (contributing factors) identified for this survey using SPSS Version 21 for Windows. Secondly, all the scales tested in this study had Cronbach's Alpha values above 0.7, except the perceived control and the perceived knowledge, which showed a reliability of 0.68 and 0.62 , respectively. According to Pallant [26], researchers often accept values that range between 0.6 and 0.7 when scales consist of ten items or less; and a decision was made to retain these two components. Thirdly, a discriminant analysis was conducted to predict group membership. More specifically, a stepwise discriminant analysis was performed using the confirmed components (as identified through the PCA) to establish the relationship between the independent variables (contributing factors in this case) in terms of their relative importance, and the dependent variable (groups created based on consumers' attitudes towards SMS advertisements) [17]. This entailed a process of selection and retention of the independent variables based on these variables meeting the significance criteria for inclusion and retention in the discriminant function [17]. The final step in assessing the discrimination value was to evaluate the percentage share of cases that would be classified correctly on the basis of the discrimination functions.

\section{$4 \quad$ Research results}

\subsection{Principal Components Analysis}

Before the discriminant analysis procedure was conducted, a component analysis was performed on the 40 items measuring the contributing factors to consumers' attitudes towards SMS advertisements. The Kaiser-Meyer-Olkin measure of sampling adequacy result indicated a statistically significant value of 0.86 , supporting the factorability of the component matrix [26]. The final PCA revealed the presence of eight components with eigenvalues exceeding one, explaining a total of $66 \%$ of the variance. The first component explained $25.4 \%$, while the second component explained $10.1 \%$ of the variance. The other components explained variances ranging between $9 \%$ and $3 \%$. To aid in the interpretation of the eight components, a Varimax rotation with Kaiser Normalisation was performed. The analysis resulted in a number of items measuring content appeal, perceived personalisation and location-based advertisements loading onto one component. This component was later labelled "perceived SMS infotainment" because the combined three items all describe ways to draw the attention of respondents to SMS advertising. The final rotated eight-component solution comprised (1) perceived SMS infotainment, (2) fear of spamming, (3) perceived incentives, (4) consumer innovativeness, (5) interactivity of SMS advertisements, (6) perceived control, (7) consumer knowledge and (8) attitudes towards advertising in general. 


\subsection{Results of the discriminant analysis}

The eight contributing factors were included in the discriminant analysis procedure. The procedure was applied to determine the value of the composite variables for classification and predictive purposes, as well as the discriminating value of each of the eight factors generated from the PCA.

For the analysis, two mutually exclusive groups were created. Group 1 denoted consumers who scored 1, 2, 3 and 4 on the Likert scales measuring consumers' attitudes towards SMS advertisements and represented the respondents with a lower favourability of SMS advertisements. Group 2 comprised consumers who scored 5, 6 and 7 on the same Likert scales and represented respondents with a higher favourability towards SMS advertising.

The eigenvalues associated with this function was 0.278 and accounted for $100 \%$ of the explained variance. The canonical correlation associated with this function was 0.466 , indicating that $21.7 \%$ of the variation in the dependent variable was explained or accounted for by this model, that is, whether a group has a favourable attitude towards SMS advertisements or not.

Before interpreting the results, the discriminant function estimate has to be statistically significant. In SPSS, the test of the null hypothesis is based on an F transformation of Wilks' lambda. Wilks' lambda identified a statistically significant discriminant function at the 0.000 level. The Wilks' lambda associated with the discriminant function was 0.783 , which transforms to a Chi-Square of 73.644 with 3 degrees of freedom. This indicates that the mean test scores between the two groups are statistically significant at significance levels exceeding 0.05 .

An examination of the absolute magnitude of the standardised discriminantfunction coefficients indicates the relative importance of the variables. These coefficients describe the relative contribution of each factor in determining the selection or non-selection of the two groups. The larger the standardised coefficient, the greater the contribution of the respective variable to the discrimination between groups. It is important to note that five of the eight factors did not meet the significance criteria for inclusion and retention in the stepwise discriminant-function analysis. Three standardised canonical-discriminant coefficients met the significance criteria for inclusion and retention of the factors, namely perceived SMS attractiveness $(0.886)$, fear of spamming (-0.368) and perceived knowledge (0.378).

The findings indicate that perceived SMS attractiveness $(0.886)$ is the most single powerful discriminator among the three factors under consideration. There was a minimum difference between perceived knowledge (0.378) and fear of spamming (0.368; a negative relationship). An inspection of the mean discriminant scores (centroids) for each group reveals acceptable discrimination, as the mean values vary considerably between negative (-0.554) and positive scores (4.98) for Group 1 and Group 2 respectively.

The final criterion for assessing the discrimination value is the percentage share of cases that would be classified correctly on the basis of the discrimination functions. Many researchers use the structure matrix correlations because they are considered 
more accurate than the standardised canonical discriminant function coefficients [17]. Table 1 shows the results in a classification matrix.

Table 1. Classification matrix for two group prediction

\begin{tabular}{|l|c|c|}
\hline \multicolumn{1}{|c|}{ Actual Group } & $\begin{array}{c}\text { Predicted Group 1 } \\
(\mathbf{\%})\end{array}$ & $\begin{array}{c}\text { Predicted Group } \\
\mathbf{2}(\mathbf{\%})\end{array}$ \\
\hline Group 1: Less favourable attitudes towards SMS advertisements & 62.5 & 37.5 \\
\hline $\begin{array}{l}\text { Group 2: More favourable attitudes towards SMS advertise- } \\
\text { ments }\end{array}$ & 26.3 & 73.8 \\
\hline
\end{tabular}

The classification procedure is set to maximise the hit rates; that is, the correct number of classifications [17]. Overall, $68.4 \%$ of the respondents were classified correctly into the two groups. This suggests that practitioners can consider these two groups in order to fully understand and implement successful SMS advertising campaigns. Consumers who hold more favourable attitudes towards SMS advertisements were classified with better accuracy $(73.8 \%)$ than consumers who are less favourable towards SMS advertisements $(62.5 \%)$.

Ideally, any classification accuracy achieved by discriminant analysis should be approximately $25 \%$ greater than that obtained by chance to give confidence [21]. Most discriminant analysis programmes also estimate a classification matrix based on the analysis sample. As they capitalise on chance variation in the data, such results are invariably better than the classification obtained on the sample [21]. The following calculations were made to determine whether the model in Table 1 has satisfactory predictive power. First, the proportional-chance criterion was calculated to evaluate the validity of the framework. This criterion took a value of $50 \%\left[(144 / 304)^{2}+\right.$ $\left.(160 / 304)^{2}\right]$, while $68.4 \%$ of the cases were correctly classified with this function. This means that overall classification accuracy was higher than the proportionalchance criterion value $(68.4 \%>50 \%)$. The chance criterion was then used to evaluate whether the present function achieved a $25 \%$ margin. The percentage of cases correctly classified in the present model was higher than the chance criterion $(68.4 \%>62.5 \%$ $=50 \times 1.25$ ). Thus, the results of this study led to the proposal of a framework containing three factors that are responsible for discriminating consumers on the basis of their attitudes towards SMS advertisements.

\section{$5 \quad$ Discussion and conclusion}

This study contributes to simplifying the conceptual framework with regard to the number of factors affecting consumers' attitudes towards SMS advertisements. The results from this study identified three factors (perceived SMS infotainment, perceived knowledge and fear of spamming) that can reliably be used to separate consumers with positive and less positive attitudes towards SMS advertising. The findings thus offer a framework that enables the prediction of consumers' responses to SMS advertisements in a consistently favourable or unfavourable manner. 
The most significant differentiator of consumers' attitudes towards SMS advertisements is perceived SMS infotainment. Since this factor is a result of three separate factors from the PCA, it suggests that perceived personalisation, content appeal and location-based advertising must be given due consideration in the design of SMS advertisements, as discussed below.

While personalisation is important, attention needs to be paid to the relevance and timeliness of the message. As reported by Dolnicar and Jordaan [11], technologybased systems have made it easy and affordable for practitioners to collect, store, use, and share information with others. Advertisers must constantly mine data related to consumers' needs and preferences so that they can develop and send appropriate SMS messages that match consumers' profiles and expectations [45]. The challenge that media practitioners face is to develop messages that are short, straightforward and relevant to consumers' needs and interests. In a study by Orr et al. [25], participants suggested that messages that are too confrontational and contain negative words should be avoided in SMSs and be replaced by supporting and motivating messages. The value of the customer offering is also increased when messages are personalised based on their shopping locations. The Bluetooth function enables advertisers to send instant messages about products to consumers within the vicinity [28]. A previous study indicated that because of security concerns, consumers do not always turn on their Bluetooth function [5]. This poses a challenge to media practitioners who need to send these instant messages to consumers to solicit the purchase of nearby products and services. Thus, from the above, suffice it to say that if the SMS contains relevant information that addresses the current needs of the consumer, and if the message is received timeously with the right frequency, it is considered attractive and effective.

Perceived knowledge, which emerged as the second differentiator, implies that consumers who are not familiar with the application, or who find the mobile interface design complex, particularly elderly consumers [43], may hold negative attitudes towards SMS advertisements. Since not all consumers own smartphones, messages should take the standard form of SMS messages that can be received and displayed on any mobile device. Yang et al. [44] reported that the users' experience with mobile services may increase or decrease access to mobile advertisements and actual use. Media planners targeting older consumers must overcome the challenge that can be posed by user knowledge and experience, because a consumer who experiences difficulties in using the SMS application, may have a negative attitude towards SMS advertisements. It has been widely reported that the youth are more innovative and accept SMS advertisements more readily than older consumers because of their knowledge of the application [39].

Fear of spamming emerged as the third differentiating factor of consumers' attitudes towards SMS advertisements. As SMS advertisements are transmitted via a personalised device, they are vulnerable to being perceived as spam if the messages are sent indiscriminately. Advertisers are encouraged to reinforce the attractiveness of SMSs and decrease the annoying messages, which can be achieved through reinforcing permission-based strategies [42]. One study reported that consumers who attach great importance to privacy, do not attribute a high value to SMS advertisements [32]. Therefore the key to improving acceptance of SMS advertisements that are not re- 
garded as spam is to ask consumers' permission to receive the SMSs. In South Africa, the Wireless Application Service Providers Association (WASPA) was formed to protect consumers from unscrupulous businesses that spam consumers with unsolicited SMSs. Consumers can lodge a complaint directly with WASPA if they feel that they have been spammed [40]. The WASPA code of conduct encourages companies to incorporate the opt-in, opt-out option to any SMS advertisement to mitigate the influx of intrusive SMSs. Dolnicar and Jordaan [11] warned that unless practitioners begin to implement responsible and ethical information-handling practices, there may be few customers to manage in future.

\section{$6 \quad$ Limitations and directions for future studies}

Data were collected from a convenience sample of 304 participants, living in only one of the nine provinces in South Africa at the time of the survey, which may have resulted in sampling bias. For purposes of generalisability of findings, future studies can collect data from other provinces in the country to confirm or challenge the findings of this study.

Furthermore, this study focussed on adult consumers aged 25 years and older. Future studies can investigate the same factors among both the youth and young adults in one study (below 25 years of age). The comparison of the results will provide a full spectrum of consumers with regard to higher favourable attitudes as opposed to lower favourable attitudes towards SMS advertisements. The contributing factors that were investigated in this study represent a simplified framework. Other factors that could potentially play an important role in shaping consumers' attitudes towards SMS advertisements were excluded. Notably, these could be psychological factors such as motivation, perception and personality, as well as group factors such as culture and social class.

\section{Conclusion}

The findings of this study suggest that the planning of SMS campaigns should be based on the attractiveness of the SMS, including the benefits of the SMS, it being informative, and sent only once permission has been obtained. Media practitioners should look forward to SMSs as the future trend in advertising. Overall, findings support earlier literature that successful SMS campaigns are those that are relevant, highly targeted, personalised, time and location relevant. Spamming should be avoided because it may backfire on the sender and damage the integrity of SMSs. It can be concluded, therefore, that media practitioners can receive the greatest acceptance from SMS campaigns from consumers who hold positive attitudes towards advertising in general. 


\section{$8 \quad$ References}

[1] M. Andrews, J. Goehring, S. Hui, J. Pancras, and L. Thornswood, "Mobile Promotions: A Framework and Research Priorities", Journal of Interactive Marketing, vol. 34, pp. 15-24, 2016. https://doi.org/10.1016/j.intmar.2016.03.004

[2] W. Aslam, M. Batool, and Z. U1 Haq, "Attitudes and behaviour of the mobile phones users towards SMS advertising: a study in an emerging economy," Journal of Management Sciences, 3(1), pp. 63-80, 2016. https://doi.org/10.20547/jms.2014.1603105

[3] B. J. Babin and E. G. Harris, Eds., Consumer Behaviour. South-Western Cengage Learning, 2014.

[4] N. S. Baron, and Y.H. Segerstad, "Cross-cultural patterns in mobile-phone use: Public space and reachability in Sweden, the USA and Japan," New Media \& Society, vol. 12, no. 1, pp. 13-34, 2010. https://doi.org/10.1177/1461444809355111

[5] J. Beneke, G. Cumming, A. Stevens, and M. Versfeld, "Influences on attitude towards mobile text message advertisements: An investigation of South African youth," International Journal of Mobile Marketing, vol. 5, no. 1, pp. 77-98, 2010.

[6] BusinessTech,. "SA mobile share in 2018: Vodacom vs MTN vs Cell C vs Telkom," 2018. [Online], Available: https://businesstech.co.za/news/mobile/232795/sa-mobileshare-in-2018-vodacom-vs-mtn-vs-cell-c-vs-telkom/, [Accessed May, 25, 2018].

[7] P. T. Chen, and H. P. Hsieh, "Personalised mobile advertising: Its key attributes, trends, and social impact," Technological Forecasting \& Social Change, vol. 79, pp. 543-557, 2012. https://doi.org/10.1016/j.techfore.2011.08.011

[8] C. K. Coursaris, and J. Sung, "Antecedents and consequents of a mobile website's interactivity," New Media \& Society, vol. 14, no. 7, pp. 1128-1146, 2012. https://doi.org/10.1177/1461444812439552

[9] G. M. S. Dann, "Tourist motivation: An appraisal," Annals of Tourism Research, vol. 8, pp. 187-219, 1981. https://doi.org/10.1016/0160-7383(81)90082-7

[10] S. Dix, K. Jamieson, and A. S. Shimul, "SMS advertising the Hallyu way: Drivers, acceptance and intention to receive," Asia Pacific Journal of Marketing and Logistics, vol. 28, pp. 366-386, 2016. https://doi.org/10.1108/APJML-09-2015-0146

[11] S. Dolnicar, and Y. Jordaan, "A market-oriented approach to responsibly managing information privacy concerns in direct marketing," Journal of Advertising, vol. 36, no. 2, pp. 123-149, 2007. https://doi.org/10.2753/JOA0091-3367360209

[12] D.A. Drossos, G. M. Giaglis, and P. A. Vlachos, "Consumer responses to SMS advertising: Antecedents and consequences," International Journal of Electronic Commerce, vol. 18, no. 1, pp. 105-136, 2013. https://doi.org/10.2753/JEC1086-4415180104

[13] M. Fishbein and I. Ajzen, Eds., Belief, Attitude, Intention, and Behaviour: An Introduction to Theory and Research, Reading, MA: Addison-Wesley, 1975.

[14] G. R. Foxall, R. E. Goldsmith, and S. Brown, Eds., Consumer Psychology for Marketing, 2nd ed. South-Western Cengage Learning, 1998.

[15] Q. Gao, P. L. P. Rau, and G. Salvendy, "Measuring perceived interactivity of mobile advertisements," Behaviour \& Information Technology, vol. 29, no. 1, pp. 35-44, 2010. https://doi.org/10.1080/01449290802666770

[16] T. Gao, A. J. Rohm, F. Sultan, and S.Huang, "Antecedents of consumer attitudes toward mobile marketing: A comparative study of youth markets in the United States and China," Thunderbird International Business Review, vol. 54, no. 2, pp. 211-224, 2012. https://doi.org/10.1002/tie.21452

[17] J. F. Hair, W. C. Black, B. J. Babin, R. E. Anderson, and R. L. Tatham, Eds., Multivariate Data Analysis, 6th ed. Pearson: Prentice Hall, 2006. 
[18] M. Humbani, T. Kotze, and Y. Jordaan, "Predictors of consumer attitudes towards SMS advertising," Management Dynamics, vol. 24, no. 2, pp. 2-19, 2015.

[19] Y. Jordaan, and M. N. Simpson, "Consumer innovativeness among females in specific fashion stores in the Menlyn shopping centre," Journal of Family Ecology and Consumer Sciences, vol. 34, no. 1, pp. 32-40, 2006.

[20] M. Kwasawneh, and A. Shuhaiber, "A comprehensive model of factors influencing attitude towards and acceptance of SMS advertising: An empirical investigation in Jordan," International Journal of Sales \& Marketing Management Research and Development, vol. 31, no. 2, pp. 1-22, 2013.

[21] N. K. Maholtra, Review of Marketing Research, Emerald Group Publishing Ltd, 2004.

[22] F. F. M. Mhiadjo, and P. Djeumene, "Factors explaining the adoption of mobile marketing in Cameroon: Exploratory study on the use of SMS as method of transmission of social information," African Journal of Marketing Management, vol. 7, no. 2, pp. 20-31, 2015. https://doi.org/10.5897/AJMM2014.0430

[23] R. Nittala, "Registering for incentivized mobile advertising: Discriminant analysis of mobile users," International Journal of Mobile Marketing, vol. 6, no. 1, pp. 42-51, 2011.

[24] S. Okazaki, and C. R. Taylor, "What is SMS advertising and why do multinationals adopt it? Answers from an empirical study in European markets," Journal of Business Research, vol. 6, no. 1, pp. 4-12, 2008. https://doi.org/10.1016/j.jbusres.2006.05.003

[25] J. A. Orr, R. J. King, P. Hawke, and J. Dalgleish, "Can we text you? A qualitative exploration of young unemployed job-seekers' attitudes to receiving resilience-building SMS messages," Advances in Mental Health, vol. 11, no. 3, pp. 268-285, 2013. https://doi.org/10.5172/jamh.2013.11.3.268

[26] J. Pallant, SPSS Survival Manual: A Step-by-Step Guide to Data Analysis Using SPSS Program, 4th ed. Australia: Allen \& Unwin, 2011.

[27] J. M. Parreno, S. Sanz-Blas, C. Ruiz-Mafe, and J. Aldas-Manzano, "Key factors of teenagers' mobile advertising acceptance," Industrial Management \& Data Systems, vol. 113, no. 5, pp. 732-749, 2013. https://doi.org/10.1108/02635571311324179

[28] L. Pen, R. Chen, J. Liu, H. Kuusniemi, T. Tenhunen, and Y. Chen, "Using Inquiry-based Bluetooth RSSI probability distributions for indoor positioning," Journal of Global Positioning Systems, vol. 9, no. 2, pp. 122-130, 2010.

[29] I. Phau, and M. Teah, "Young consumers' motives for using SMS and perceptions towards SMS advertising," Direct Marketing: An International Journal, vol. 3, no. 2, pp. 97 108, 2009. https://doi.org/10.1108/17505930910964768

[30] L. Radder, J. Pietersen, and H. Wang, "Antecedents of South African high school pupils' acceptance of universities' SMS advertising," International Business \& Economics Research Journal, vol. 9, no. 4, pp. 29-40, 2010.

[31] H. E. Riquelme, R. E. Rios, and S. O. Enezi, "Drivers of three SMS ad responses," Journal of Targeting, Measurement and Analysis for Marketing, vol. 20, no. 1, pp. 1-15, 2011. https://doi.org/10.1057/jt.2011.14

[32] I. Roozen, and E. Genin, "Can we compare SMS marketing to traditional marketing communications?," Hub Research Paper, 2008/50, 1-29, 2008.

[33] Statista, "Mobile internet advertising spending worldwide from 2015 to 2020," Statista, 2018. [Online], Available: https://www.statista.com/statistics/280640/mobile-advertisingspending-worldwide/, 2018. [Accessed May, 25, 2018].

[34] R. Sooryumoorthy, "Inside the mobile world and outside the Internet," New Media \& Society, vol. 16, no. 1, pp. 165-170, 2014. 
[35] M. M. Tsang, S. C. Ho, and T. P. Liang, "Consumer attitudes toward mobile advertising: An empirical study," International Journal of Electronic Commerce, vol. 8, no. 3, pp. 6578, 2004. https://doi.org/10.1080/10864415.2004.11044301

[36] S. Unal, A. Ercis, and E. Keser, "Attitudes towards mobile advertising: A research to determine the differences between the attitudes of youth and adults," Procedia Social and Behavioural Sciences, vol. 24, pp. 361-377, 2011. https://doi.org/10.1016/j.sbspro. 2011.09.067

[37] D. L. R. Van der Waldt, T. M. Rebello, and W. J. Brown, "Attitudes of young consumers towards SMS advertising," African Journal of Business Management, vol. 3, no. 9, pp. 444-452, 2009.

[38] D. Vigar-Ellis, L. Ellis, and C. Barraclough, "Perceptions towards SMS marketing: An exploratory investigation," Management Dynamics, vol. 16, no. 2, pp. 16-23, 2007.

[39] Wireless Application Service Providers Association. "Code of Practice for Commercial SMS," 2013. Wireless Application Service Providers Association [Online], Available: https://www.waspa.org.za, [Accessed Aug, 12, 2015].

[40] R. Wei, H. Xiaoming, and J. Pan, "Examining user behavioural response to SMS ads: Implications for the evolution of the mobile phone as a bona-fide medium," Telematics and Informatics, vol. 27, no. 1, pp. 32-41, 2010. https://doi.org/10.1016/j.tele.2009.03.005

[41] R. Wells, C. E. Kleshinski, and T. Lau, "Attitudes toward and behavioural intentions to adopt mobile marketing: Comparison of Gen Y in the United States, France and China," Mobile Marketing Association, vol. 7. No. 2, pp. 5-25, 2012.

[42] W. Xie, Y. Zhao, and W. Xie, "The effects of interface design of hand-held devices on mobile advertising effectiveness among college students in China," International Journal of Mobile Marketing, vol. 8, no. 1, pp. 46-57, 2013.

[43] B. Yang, Y. Kim, and C. Yoo, "The integrated mobile advertising model: The effects of technology-and emotion-based evaluations," Journal of Business Research, vol. 66, no. 9, pp. 1345-1352, 2013. https://doi.org/10.1016/j.jbusres.2012.02.035

[44] A. M. A. Zabadi, M. Shura, and E. A. Elsayed, "Consumer attitudes towards SMS advertising among Jordanian users," International Journal of Marketing Studies, vol. 4, no. 1, pp. 77-94, 2012. https://doi.org/10.5539/ijms.v4n1p77

[45] M. Leppaniemi, and H. Karjaluoto, "Factors influencing consumers' willingness to accept mobile advertising: a conceptual model," International Journal of Mobile Communications, vol. 3, no. 3, pp. 197-213, 2005. https://doi.org/10.1504/IJMC.2005.00 $\underline{6580}$

\section{Authors}

Michael Humbani is a lecturer in the Department of Marketing Management at the University of Pretoria. His current research focuses primarily on consumer behaviour within the new media environment.

Professor Yolanda Jordaan is the Head of the Department of Marketing Management at the University of Pretoria. Her research interests are consumer information privacy, higher education marketing, and consumer decision-making in new media.

Article submitted 05 June 2018. Resubmitted 20 July 2018. Final acceptance 11 August 2018. Final version published as submitted by the authors. 